\title{
Review
}

\section{C0VID-19 and Myocarditis: What Do We Know So Far?}

\author{
Ashar Pirzada, MD, MSc, ${ }^{a}$ Ahmed T. Mokhtar, MBBS, FRCPC, a,b and \\ Andrew D. Moeller, MD, MASc, FRCPC ${ }^{a}$ \\ ${ }^{a}$ Division of Cardiology, Department of Medicine, Dalhousie University, Halifax, Nova Scotia, Canada \\ ${ }^{b}$ Department of Medicine, King Abdulaziz University, Jeddah, Saudi Arabia
}

\begin{abstract}
COVID-19 has been declared a global pandemic by the World Health Organization and is responsible for hundreds of thousands of deaths worldwide. COVID-19 is caused by SARS-CoV-2, and common clinical symptoms include fever, cough, sore throat, headache, and fatigue. Myocardial injury is relatively common in patients with COVID-19, accounting for $7 \%-23 \%$ of cases, and is associated with a higher rate of morbidity and mortality. There is a discrepancy in the literature about
\end{abstract}

\section{RÉSUMÉ}

La COVID-19 a été déclarée pandémie mondiale par l'Organisation Mondiale de la Santé et elle est responsable de centaines de milliers de décès dans le monde. La COVID-19 est causée par le SARS-CoV-2, et les symptômes cliniques courants sont la fièvre, la toux, le mal de gorge, les maux de tête et la fatigue. Les lésions myocardiques sont relativement fréquentes chez les patients atteints de la COVID-19, représentant 7 à $23 \%$ des cas, et sont associées à un taux de
COVID-19 has been declared as a global pandemic by the World Health Organization. ${ }^{1,2}$ COVID-19 is a clinical syndrome caused by SARS-CoV-2. The hallmark of COVID-19 is respiratory involvement, ranging from mild upper respiratory symptoms to acute respiratory distress syndrome (ARDS). ${ }^{2}$ However, severe COVID-19 imparts multiorgan involvement, with several observational case series showing a significant proportion of cardiac involvement among hospitalized patients. ${ }^{3,4}$ In addition, cardiac injury has shown disproportionate rates of mortality, with rates approaching $51 \%$ when cardiac involvement has been established. ${ }^{3}$ COVID-19 has a wide spectrum of cardiovascular complications, including acute-onset heart failure, arrhythmias, acute coronary syndrome, myocarditis, and cardiac arrest. ${ }^{3,4}$ Myocarditis is a potentially lethal complication, observed among cases of the current and previous outbreaks of other coronaviridae, such as MERS. ${ }^{5-8}$ Because of the relative novelty of COVID-19, the data surrounding the association between COVID-19 and myocarditis are still being published. The aim of this

Received for publication April 26, 2020. Accepted May 20, 2020.

Ethics Statement: This research has adhered to the relevant ethical guidelines.

Corresponding author: Dr Ahmed T. Mokhtar, Division of Cardiology, Department of Medicine, Dalhousie University, 1796 Summer St, Room 2132, Halifax Infirmary, Halifax, Nova Scotia B3H 3A7, Canada. Tel.: +1902-473-7044; fax: +1-902-473-2434

E-mail: ahmed.mokhtar@dal.ca

See page 283 for disclosure information. review was to examine the most updated literature surrounding COVID-19 and myocarditis.

\section{What Pathophysiologic Mechanisms Are Involved in COVID-19-Associated Cardiac Disease?}

The exact pathophysiology of severe COVID-19 disease is still elusive. However, a consistent observation is the presence of a proinflammatory surge, the so-called "cytokine storm." This is thought to be central to the pathogenesis of the acute lung injury-acute respiratory distress syndrome spectrum that amplifies the immune response of alveolar tissue. ${ }^{9-11}$ This phenomenon is thought to be a contributory factor to myocardial injury, observed in other forms of viral infections, such as $\mathrm{H} 1 \mathrm{~N} 1{ }^{12}$ Huang et al. showed this among a cluster of 41 patients with COVID-19. Patients who required intensive care $(\mathrm{n}=13)$ showed higher plasma concentrations of cytokines and chemokines, including GCSF, IP10, MCP1, MIP1A, and tumour necrosis factor $\alpha$. However, it is unknown if myocarditis is the actual cause of the troponin increase in this case series, because the authors did not report data showing correlative cardiac outcomes or demonstration of left ventricular dysfunction.

Chen and colleagues also had a similar observation, with elevation of interleukin (IL)-2R, IL-6, IL-10, and tumour necrosis factor $\alpha$ among the cohort of severe COVID-19 patients in a single-centre retrospective study. ${ }^{11}$ Cytokine storm is not unique to severe COVID-19, because MERS$\mathrm{CoV}$ and SARS-CoV have shown cytokine surge syndrome 
myocarditis as the etiology of myocardial injury in patients with CoVID19; although many anecdotal reports of myocarditis have been noted, there are only a handful of case reports in the literature about myocarditis related to COVID-19. In this review we summarize the most up to date literature around the association between COVID-19 and myocarditis and provide clinicians a practical framework about the clinical manifestations, diagnostic tools, and treatment options currently available. Importantly, this review will heighten suspicion for myocarditis as an etiology of myocardial injury in COVID-19 patients, therefore improving clinical outcomes and encouraging shared clinical decision-making. This will also open the door for further research to build around this review. Emergent treatment options for COVID-19 are in clinical trials and might be of benefit to COVID-19 patients with myocarditis in addition to current guideline-based recommendations. morbidité et de mortalité plus élevé. II existe des divergences dans la littérature décrivant la myocardite en tant qu'étiologie de lésions myocardiques chez les patients atteints de la COVID-19; bien que de nombreux rapports anecdotiques de myocardite aient été rapportés, il n'y a qu'un nombre limité de rapports de cas dans la littérature concernant des myocardites liées à la CovID-19. Dans cette revue de littérature, nous résumons la bibliographie la plus récente sur l'association entre COVID-19 et myocardite et fournissons aux cliniciens un cadre pratique sur les signes cliniques, les outils de diagnostic et les options de traitement actuellement disponibles. II est important de noter que cette revue augmentera la suspicion de myocardite comme étiologie de lésions myocardiques chez les patients atteints de la COVID-19, améliorant ainsi le pronostic clinique et encourageant une prise de décision clinique partagée. Cela ouvrira également la voie à d'autres recherches qui pourront s'appuyer sur cette étude. De nouvelles options de traitement de la COVID-19 sont en cours d'essais cliniques et pourraient être bénéfiques aux patients atteints de la COVID-19 qui présentent une myocardite, tout en étant considérées pour les recommandations actuelles basées sur les lignes directrices.

Wuhan University, 82 patients (19.7\%) had cardiac injury. Mortality among the myocardial injury group was significantly higher $(51.2 \%$ vs $4.5 \% ; P<0.001)$. Cardiac involvement among this cohort of patients showed a hazard ratio of 4.26. Ruan et al. reported a multicentre, retrospective review of 150 patients with confirmed COVID-19. ${ }^{20}$ Sixty-eight patients died, with 5 patients (7\%) dying of heart failure and 22 patients (33\%) dying of respiratory and heart failure. The cohort with a higher rate of death consistently had higher levels of troponin and myoglobin. The authors speculate that some of these patients died of COVID-19-induced fulminant myocarditis, but no reports on autopsies or biopsies were provided. myocardial involvement was seen in MERS, with one report showing evidence of subepicardial late gadolinium enhancement, consistent with myocarditis. ${ }^{6}$ In this case, the distribution of late gadolinium enhancement in the subepicardial region is consistent with myocarditis.

So far, there are limited reports showing pathological evidence that COVID-19 directly invades the heart. ${ }^{18}$ Sala et al. showed viral particles with the morphology and size of coronaviruses in interstitial macrophages, however, there was no SARS-CoV-2 genomic material in the myocardium. In another study, $\mathrm{Xu}$ et al. reported pathological postmortem biopsies from a patient who succumbed to COVID-19. There were only a few interstitial mononuclear inflammatory infiltrates, but no other substantial damage in the heart tissue. ${ }^{4}$

\section{How Common Is Cardiac Involvement in Patients With Covid-19?}

Outside of published case reports, the exact incidence of myocardial involvement or myocarditis among hospitalized COVID-19 patients is unknown. However, several observational studies have reported cardiac injury among hospitalized COVID-19 patients. ${ }^{3,19,20}$ In most reports myocardial injury is defined as detectable serum troponin level above the 99th percentile of the upper reference limit. So far, the largest study to examine the association between cardiac involvement and COVID-19 was performed at the index epicentre in China. ${ }^{3}$ From a cohort of 416 patients at the Renmin Hospital of

\section{What Are the Symptoms of Myocarditis Among COVID-19 Patients?}

Myocarditis can have a variety of clinical presentations, ranging from mild symptoms such as fatigue, chest pain, and palpitations to life-threatening presentations such as cardiogenic shock or sudden cardiac death associated with ventricular arrhythmias (Fig. 2). ${ }^{21}$ Classically, myocarditis has a viral prodrome including fevers, myalgias, and respiratory/gastrointestinal symptoms but this can be exceedingly variable, with ranges of $10 \%-80 \%{ }^{22,23}$ Myocarditis is more common in men, with a male/female ratio between $1.5: 1$ and $1.7: 1 .^{24}$

COVID-19 patients predominantly present with fever, cough, and dyspnea. ${ }^{23} \mathrm{~A}$ meta-analysis of 10 studies including 1995 COVID-19 patients showed that common symptoms were fever $(88.5 \%)$, cough $(68.6 \%)$, myalgia or fatigue (35.8\%), expectoration (28.2\%), and dyspnea (21.9\%); minor symptoms included headache or dizziness $(12.1 \%)$, diarrhea $(4.8 \%)$, and nausea and vomiting $(3.9 \%) .{ }^{23}$ Other infrequent symptoms such as abdominal pain, constipation, chest pain, palpitations, chills, and anorexia accounted for $7 \%-42 \%$ of presentations altogether. ${ }^{21}$

A cohort study from Wuhan, China involving 416 hospitalized patients with confirmed COVID-19 infection Hospitalized patients with an increase of troponin level were showed that chest pain accounted for $3.4 \%$ of presentations. ${ }^{3}$ 


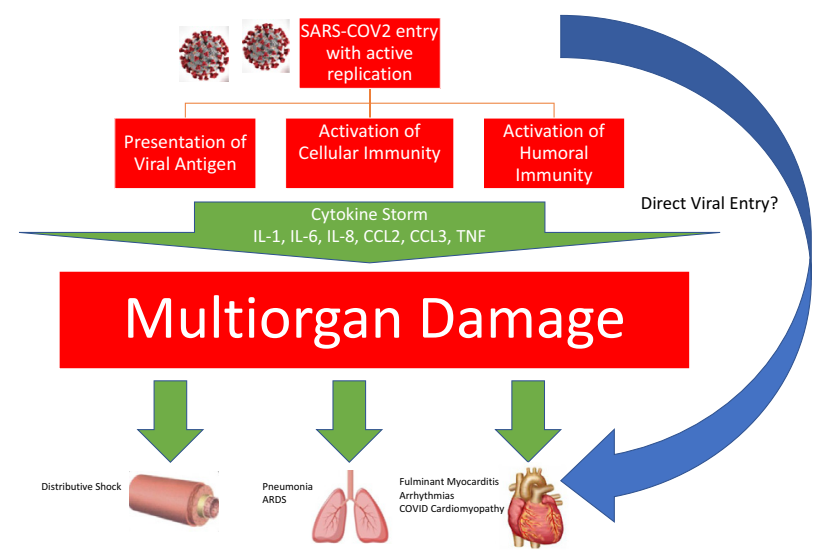

Figure 1. Mechanisms of pathogenesis and systemic effects of COVID-19 leading to multiorgan damage. ARDS, acute respiratory distress syndrome; CCL2, C-C motif chemokine ligand 2; CCL3, C-C motif chemokine ligand 3; IL, interleukin 1; SARS-COV2, severe acute respiratory syndrome coronavirus 2; TNF, tumour necrosis factor $\alpha$.

more likely to present with chest pain than those without an increase of troponin level (11 of 82 patients [13.4\%] vs 3 of 334 patients [0.9\%]; $P<0.001)$. Established myocarditis is a relatively rare sequelae of COVID-19 infection. In the reported COVID-19 cases with myocarditis in the literature, clinical presentations have varied (Table 1). There is potential overlap in symptomatology in patients with primary COVID19 infection and COVID-19 patients with clinically suspected myocarditis.

\section{How Can Myocarditis Among Covid-19 Patients Be Diagnosed?}

Significant serum troponin elevation has been observed among several cases of severe COVID-19, which might indicate cardiac involvement. ${ }^{25}$ A study by Zhou et al. showed that high-sensitivity troponin I levels were significantly greater by day 4 in COVID-19 nonsurvivors vs survivors $(8.8 \mathrm{pg} / \mathrm{mL}$ vs $2.5 \mathrm{pg} / \mathrm{mL}$ ). Myocardial injury is a predictor of mortality and more severe illness in COVID-19-confirmed patients. ${ }^{26}$ However, troponitis in isolation is not diagnostic of myocarditis and requires other supplementary findings and investigations. Furthermore, troponin elevation in the setting of severe COVID-19 could be a reflection of supply demand mismatch, rather than overt myocardial injury. ${ }^{27}$ Other biomarkers, such as natriuretic peptides are not sensitive or specific in diagnosing myocarditis. ${ }^{21}$

Electrocardiograms (ECGs) are usually abnormal in patients with myocarditis, however, specific abnormalities on ECG lack sensitivity and specificity. ${ }^{28}$ Dynamic ECG changes have been documented in critically ill COVID-19 patients. ${ }^{29}$ In 2 cases reported by He et al., dynamic ECG changes were noted when hospitalized COVID-19 patients clinically deteriorated. ${ }^{29}$ In one case, a patient's baseline ECG was sinus rhythm with first-degree atrioventricular (AV) block, which progressed to high-grade AV block before returning to baseline within 2 days. It was undetermined if these patients had myocarditis. Nevertheless, dynamic ECG changes in COVID19 patients might be a harbinger of clinical deterioration and should be recorded in all hospitalized COVID-19 patients.

Echocardiography is an important first-line noninvasive test in the workup for myocarditis. Transthoracic
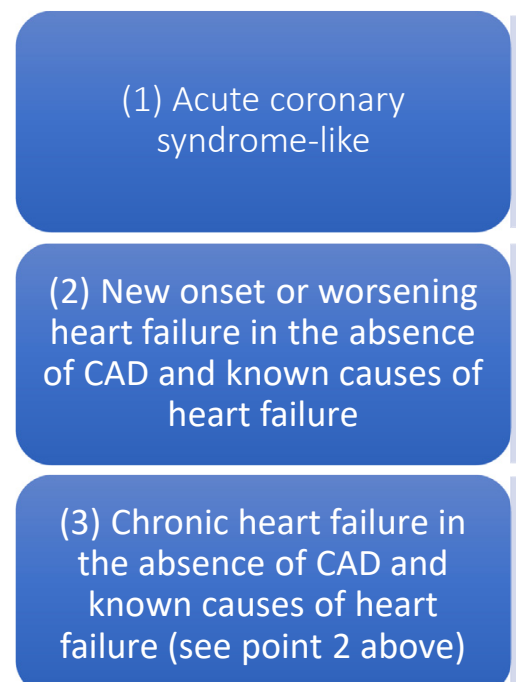

(4) 'Life-threatening condition', in the absence of CAD and known causes of heart failure comprising
- Acute chest pain

-ST/T wave changes

-With or without normal global or regional LV and/or RV dysfunction on

echocardiography or CMR

- With or without increased TnT/Tnl that may have a time course similar to acute myocardial infarction or a prolonged and sustained release over several weeks or months

- New onset or progressive heart failure over 2 weeks to 3 months

- Impaired systolic LV and/or RV function, with or without an increase in wall thickness, with or without dilated LV and/or RV on echocardiography or CMR

- Symptoms possibly started after a respiratory or gastrointestinal infection, or

in the peri-partum period

- Non-specific ECG signs, bundle branch block, AV-block, and/or ventricular arrhythmias

- Heart failure symptoms (with recurrent exacerbations) of $>3$ months duration

- Fatigue, palpitation, dyspnea, atypical chest pain, arrhythmia in an ambulant patient

- Impaired systolic LV and/or RV function on echocardiography or CMR

suggestive of DCM or non-ischemic cardiomyopathy

- Non-specific ECG signs, sometimes bundle branch block and/or ventricular

arrhythmias and/or AV-block

- Life-threatening arrhythmias and aborted sudden death

- Cardiogenic shock

- Severely impaired LV function

Figure 2. Clinical presentations of patients with biopsy-proven inflammatory heart muscle disease. AV, atrioventricular; CAD, coronary artery disease; CMR, cardiac magnetic resonance; DCM, dilated cardiomyopathy; ECG, electrocardiogram; LV, left ventricular; RV, right ventricular; Tnl, troponin I; TnT, troponin T. Modified from Caforio et al. ${ }^{21}$ with permission from Oxford University Press. 
Table 1. Published literature highlighting clinically suspected myocarditis in COVID-19 patients

\begin{tabular}{|c|c|c|c|c|c|c|c|c|c|}
\hline Study & Case & Clinical & Troponin & NT-proBNP & ECG & TTE & CMR & EMB & Outcome \\
\hline Inciardi et al. ${ }^{7}$ & $53 \mathrm{M}$ & $\begin{array}{l}\text { Cough } \\
\text { Fatigue } \\
\text { Fever }\end{array}$ & $\begin{array}{l}\text { Troponin } \\
\quad \text { T: } 0.24 \mathrm{ng} / \mathrm{mL}\end{array}$ & $5647 \mathrm{pg} / \mathrm{mL}$ & $\begin{array}{l}\text { Minimal diffuse ST segment } \\
\text { elevation (more prominent } \\
\text { in inferolateral leads) and ST } \\
\text { depression with } T \text { wave } \\
\text { inversion in lead } \mathrm{V}_{1} \text { and } \\
\text { aVR }\end{array}$ & LVEF $40 \%$ & $\begin{array}{l}\text { Short tau inversion recovery } \\
\text { and T2 mapping sequences } \\
\text { showing biventricular } \\
\text { myocardial interstitial } \\
\text { edema. Inversion recovery } \\
\text { sequences showing } \\
\text { biventricular wall diffuse } \\
\text { LGE }\end{array}$ & N/A & Clinical improvement \\
\hline Zeng et al. ${ }^{5}$ & $63 \mathrm{M}$ & $\begin{array}{l}\text { Chest pain } \\
\text { Cough } \\
\text { Dyspnea } \\
\text { Fever } \\
\text { Sputum }\end{array}$ & $\begin{array}{l}\text { Troponin } \\
\text { I: } 11.37 \mathrm{~g} / \mathrm{L}\end{array}$ & $22,600 \mathrm{pg} / \mathrm{mL}$ & $\begin{array}{l}\text { Sinus tachycardia, no ST } \\
\text { elevation }\end{array}$ & LVEF $32 \%$ & N/A & N/A & $\begin{array}{l}\text { ECMO as a bridge to } \\
\text { clinical recovery }\end{array}$ \\
\hline Hu et al. ${ }^{8}$ & $37 \mathrm{M}$ & $\begin{array}{l}\text { Chest pain } \\
\text { Diarrhea } \\
\text { Dyspnea }\end{array}$ & $\begin{array}{l}\text { Troponin } \\
\quad \mathrm{T}:>10,000 \mathrm{ng} / \mathrm{L}\end{array}$ & $21,025 \mathrm{ng} / \mathrm{L}$ & $\begin{array}{l}\text { ST segment elevation in } \\
\text { lead } 3, \text { aVF }\end{array}$ & LVEF $27 \%$ & N/A & N/A & Clinical recovery \\
\hline Tavazzi et al. ${ }^{18}$ & $69 \mathrm{M}$ & $\begin{array}{l}\text { Cough } \\
\text { Dyspnea } \\
\text { Weakness }\end{array}$ & $\begin{array}{l}\text { Troponin } \\
\text { I: } 4331 \mathrm{ng} / \mathrm{L}\end{array}$ & N/A & N/A & LVEF 34\% & N/A & $\begin{array}{l}\mathrm{CD} 68^{+} \text {macrophages with viral } \\
\text { particles noted. No virus in } \\
\text { cardiac myocytes }\end{array}$ & $\begin{array}{l}\text { Death from bacterial } \\
\text { sepsis }\end{array}$ \\
\hline Sala et al. ${ }^{36}$ & $43 \mathrm{~F}$ & $\begin{array}{l}\text { Chest pain } \\
\text { Dyspnea }\end{array}$ & $\begin{array}{l}\text { Troponin } \\
\quad \text { T: } 135 \mathrm{ng} / \mathrm{L}\end{array}$ & $512 \mathrm{pg} / \mathrm{mL}$ & $\begin{array}{l}\text { Atrial ectopic rhythm, mild ST } \\
\text { segment elevation in } V_{1}, V_{2} \text {, } \\
\text { aVR; reciprocal } S T \\
\text { depression in } V_{4}-V_{6}\end{array}$ & LVEF $43 \%$ & $\begin{array}{l}\text { Basal and mid-LV hypokinesis } \\
\text { with diffuse myocardial } \\
\text { edema. LGE showed } \\
\text { absence of scar and necrosis }\end{array}$ & $\begin{array}{l}\text { Diffuse T-lymphocytic } \\
\text { inflammatory infiltrates with } \\
\text { interstitial edema and } \\
\text { limited necrosis. No viral } \\
\text { genome in myocardium }\end{array}$ & Clinical recovery \\
\hline Doyen et al. ${ }^{37}$ & $69 \mathrm{M}$ & $\begin{array}{l}\text { Cough } \\
\text { Diarrhea } \\
\text { Dyspnea } \\
\text { Fever } \\
\text { Vomiting }\end{array}$ & $\begin{array}{l}\text { Troponin } \\
\text { I: } 9002 \mathrm{ng} / \mathrm{L}\end{array}$ & N/A & $\begin{array}{l}\text { Criteria for left ventricular } \\
\text { hypertrophy and diffuse } \\
\text { inverted T waves }\end{array}$ & LVEF > 50\% & $\begin{array}{l}\text { Subepicardial LGE of the apex } \\
\text { and inferolateral wall }\end{array}$ & N/A & Clinical recovery \\
\hline Coyle et al. ${ }^{38}$ & $57 \mathrm{M}$ & $\begin{array}{l}\text { Cough } \\
\text { Diarrhea } \\
\text { Dyspnea } \\
\text { Fever } \\
\text { Nausea }\end{array}$ & $\begin{array}{l}\text { Troponin } \\
\text { I: } 7.33 \mathrm{ng} / \mathrm{mL}\end{array}$ & $1300 \mathrm{pg} / \mathrm{mL}$ & $\begin{array}{l}\text { Sinus tachycardia, no ST-T } \\
\text { wave changes }\end{array}$ & $\begin{array}{l}\text { LVEF } \\
\quad 35 \%-40 \%\end{array}$ & $\begin{array}{l}\text { Diffuse biventricular and } \\
\text { biatrial edema with a small } \\
\text { area of LGE }\end{array}$ & N/A & Clinical recovery \\
\hline Luetkens et al. ${ }^{39}$ & $79 \mathrm{M}$ & $\begin{array}{l}\text { Dyspnea } \\
\text { Fatigue } \\
\text { Syncope }\end{array}$ & $\begin{array}{l}\text { Troponin } \\
\quad \mathrm{T}: 63.5 \mathrm{ng} / \mathrm{L}\end{array}$ & $1178 \mathrm{pg} / \mathrm{mL}$ & Normal & LVEF > 50\% & $\begin{array}{l}\text { Diffuse interstitial myocardial } \\
\text { edema with an increased T2 } \\
\text { signal intensity ratio. T2 } \\
\text { mapping showed diffuse } \\
\text { myocardial inflammation }\end{array}$ & N/A & Clinical recovery \\
\hline Kim et al. ${ }^{40}$ & $21 \mathrm{~F}$ & $\begin{array}{l}\text { Cough } \\
\text { Diarrhea } \\
\text { Dyspnea } \\
\text { Fever } \\
\text { Sputum }\end{array}$ & $\begin{array}{l}\text { Troponin } \\
\quad \mathrm{I}: 1.26 \mathrm{ng} / \mathrm{mL}\end{array}$ & $1929 \mathrm{pg} / \mathrm{mL}$ & $\begin{array}{l}\text { Nonspecific interventricular } \\
\text { conduction delay and } \\
\text { multiple premature } \\
\text { ventricular complexes }\end{array}$ & LVEF $<35 \%$ & $\begin{array}{l}\text { Diffuse high signal intensity in } \\
\text { the LV myocardium on T2 } \\
\text { short tau inversion recovery } \\
\text { image, and myocardial wall } \\
\text { edema. Extensive transmural } \\
\text { LGE }\end{array}$ & N/A & N/A \\
\hline
\end{tabular}

left ventricular ejection fraction, $\mathrm{M}$, male; N/A, not available; NT-proBNP, N terminal pro B type natriuretic peptide; TTE, transthoracic echocardiography. 


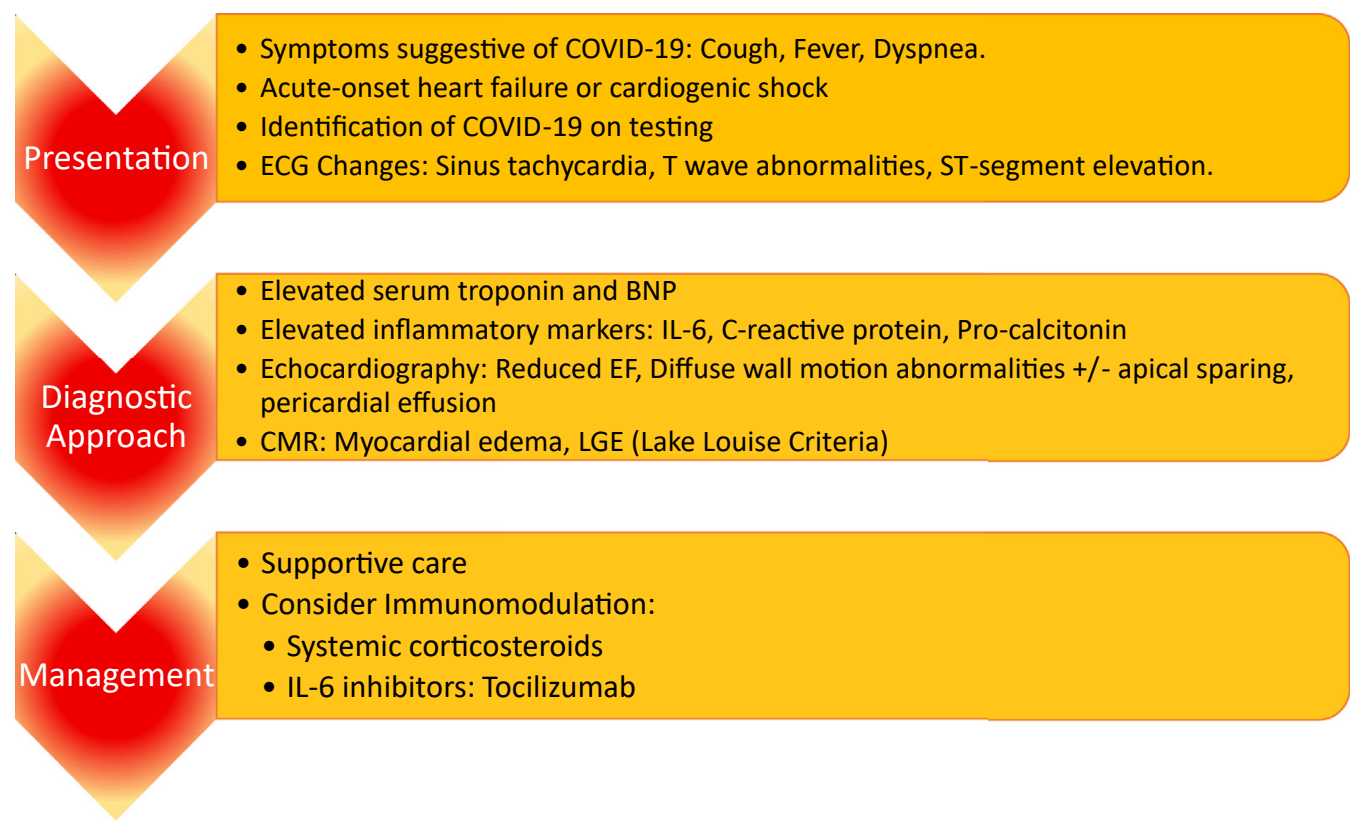

Figure 3. Summary of clinical approach of published cases of myocarditis associated with COVID-19. BNP, B type natriuretic peptide; CMR, cardiac magnetic resonance; ECG, electrocardiogram; EF, ejection fraction; IL, interleukin; LGE, late gadolinium enhancement.

echocardiography (TTE) can help rule out other causes of heart failure such as myocardial infarction and valvular heart disease. $^{30}$ TTE findings can include global left ventricular hypokinesis, regional wall motion abnormalities, and dilated and/or hypertrophic ventricles. ${ }^{31}$ In the case reports of suspected myocarditis in COVID-19 patients (Table 1), all TTEs revealed reduced left ventricular ejection fraction. Given the need for close contact to obtain images, the Canadian Society of Echocardiography recommends that among COVID-19positive or suspected patients, point-of-care ultrasound should be highly considered as an initial screening test. ${ }^{32}$ Subsequently the initial findings would determine whether a definitive TTE is required.

In typical circumstances, before the COVID-19 pandemic, cardiac magnetic resonance (CMR) imaging is an integral test in the diagnosis of myocarditis, especially if endomyocardial biopsy (EMB) is not pursued or cannot be obtained. ${ }^{33} \mathrm{CMR}$ using the Lake Louise criteria has a specificity of up to $91 \%$ and a sensitivity of $67 \%$ for diagnosing myocarditis. ${ }^{54} \mathrm{CMR}$ is not indicated in unstable patients who present with severe heart failure, circulatory shock, ventricular arrhythmia, or high-grade AV block and an EMB should be obtained. ${ }^{34}$ If CMR is available and there are no contraindications to testing, CMR can safely be used as a first-line diagnostic tool in the workup of myocarditis associated with COVID-19. ${ }^{35}$ This is documented in the current literature, because several authors have used CMR imaging to fulfil the Lake Louise criteria for diagnosing patients with myocarditis associated with COVID19. $18,36-40$ Clinical reasoning should drive the pursuit of definitive investigations when COVID-19 myocarditis is suspected.

EMB is recommended, but is not required, in certain clinical situations to aid in the diagnosis of myocarditis. ${ }^{24}$ Histologic analysis typically reveals inflammatory infiltrates with myocyte degeneration and nonischemic necrosis. ${ }^{21} \mathrm{Xu}$ et al. were the first to report interstitial mononuclear inflammatory infiltrates in a postmortem biopsy of a COVID19 patient. ${ }^{4}$ In another histopathologic study involving 3 patients, all patients had small amounts of lymphocyte, monocyte, and neutrophil infiltration in heart tissue but polymerase chain reaction did not detect COVID-19 in myocardial tissue. ${ }^{41}$ A case reported by Sala et al. showed diffuse T-lymphocytic inflammatory infiltrates $\left(\mathrm{CD}^{+}>7 /\right.$ $\mathrm{mm}^{2}$ ) with interstitial edema, but no COVID-19 genome in the myocardium. ${ }^{36}$ Furthermore, Tavazzi et al. showed viral particles typical of coronavirus involving interstitial macrophages and their surroundings, but not within the cardiac myocytes. ${ }^{18}$ Myocarditis can be an incidental finding in autopsy studies of patients who died from a noncardiac cause. Therefore, the implication of finding myocardial inflammation should always be interpreted in the context of specific clinical scenarios. ${ }^{19}$ To date, EMB evidence of direct viral invasion into myocardium has not been shown in cases of suspected COVID-19 myocarditis, which is limited by a paucity of published pathologic data.

To summarize, there is no single test or exam that allows for diagnosis of myocarditis, because the diagnosis requires a combination of clinical findings, biomarkers, imaging, and pathology when indicated.

\section{How Can Myocarditis Be Treated Among Patients With Severe Covid-19?}

There are some randomized controlled trial (RCT) data regarding management of myocarditis patients, and guideline recommendations are on the basis of expert consensus. ${ }^{42} \mathrm{~Pa}$ tients with suspected myocarditis due to COVID-19 should be treated according to current guideline recommendations for heart failure and arrhythmia. ${ }^{21,33,42}$ Heart failure is common $(>20 \%)$ in hospitalized COVID-19 patients and it is 
unclear whether this is primarily due to deterioration of preexisting left ventricular function, new-onset myocarditis, or a combination of factors. ${ }^{26}$

The routine use of steroids and other immunosuppressive strategies in all patients with myocarditis is not recommended. ${ }^{33}$ The Myocarditis Treatment Trial is the largest RCT to study immunosuppression in patients with myocarditis, which randomized 111 patients with EMB-proven myocarditis to prednisone with azathioprine, prednisone with cyclosporine, and placebo. ${ }^{43}$ There was no statistical difference in the primary end point of left ventricular ejection fraction at 28 weeks.

Systemic steroids and immunosuppression are not currently recommended for COVID-19 patients because it might exacerbate COVID-19-associated lung injury. ${ }^{44} \mathrm{~A}$ subset of these patients present with cytokine storm, and emerging data show that immunosuppression might be beneficial in these patients. ${ }^{10}$ There are ongoing clinical trials with options including steroids, intravenous immunoglobulin, selective cytokine blockade (eg, anakinra or tocilizumab), and JAK inhibition (ChiCTR2000029765). ${ }^{45}$ Although the cases of COVID-19 patients with myocarditis were treated with steroids, it is unclear the incremental benefit these therapies might have provided over supportive care. There is insufficient evidence to recommend systemic immunosuppression for suspected COVID-19 myocarditis at this time.

Antiviral therapy has been used previously in patients with viral myocarditis. However, RCTs of these therapies have not established myocarditis-causing viruses, such as enterovirus or adenovirus, as therapeutic targets. ${ }^{46}$ For example, the Betaferon in Chronic Viral Cardiomyopathy (BICC) trial randomized patients with EMB-confirmed viral cardiomyopathy to receive placebo or interferon-B. Viral clearance was not enhanced in all virus subtypes. Antiviral therapy is under investigation for the treatment of COVID-19. Lopinavir/ritonavir is a combination antiviral agent, primarily used for treatment of HIV, which is undergoing clinical trials for COVID-19. One RCT did not show any benefit in mortality compared with placebo, and lopinavir/ritonavir can be associated with long QT interval. ${ }^{47}$ To date, there is no antiviral therapy that is known to be of benefit to COVID-19 patients.

As shown in Table 1, published case reports highlight the variability in presentation of COVID-19-associated myocarditis. However, supportive therapy is still the current mainstay of management, because there is still no clear signal that any combination of immunosuppression improves outcomes among patients with myocarditis. This variability in practice is highlighted in the published case series. Steroid monotherapy, ${ }^{7,37}$ steroid and IL-6 inhibitor combination therapy, ${ }^{38}$ and antiviral monotherapy with no immunomodulation ${ }^{5}$ have all been used to date in cases of COVID-19-associated myocarditis. The benefits of immunosuppression in treating contemporary fulminant myocarditis are yet to be determined. Figure 3 shows a summary of the general clinical approach among published case reports of COVID-19-associated myocarditis.

Patients with myocarditis can clinically deteriorate or develop end-organ dysfunction despite standard heart failure therapy and supportive care. Before the COVID-19 pandemic, cases of end-stage, non-COVID-19-associated myocarditis could be referred for mechanical circulatory support (MCS) and/or consideration of heart transplantation. ${ }^{33}$ MCS as a bridge to recovery has been successful in fulminant myocarditis. ${ }^{48}$ Zhang et al. reported the first case of fulminant myocarditis requiring MCS with extracorporeal membrane oxygenator as a successful bridge to recovery in a COVID-19 patient. ${ }^{45}$ Heart transplantation would not be an option for patients with COVID-19-associated myocarditis because of their active and ongoing infection. ${ }^{33}$

\section{Summary and Future Directions}

Myocardial injury is common in patients with COVID-19, accounting for $7 \%-23 \%$ of reported cases in Wuhan, China. ${ }^{9,49,50}$ Among COVID-related myocardial injury, etiologies vary and are can include myocarditis, myocardial infarction, sepsis-related myocardial injury, and/or stressinduced cardiomyopathy. ${ }^{51}$ Further prospective cohort and case series data are needed to better characterize the exact mechanism of injury in myocarditis related to COVID-19. Because of the low prevalence of disease, this will most likely require multisite collaboration and endeavours.

Clinically suspected myocarditis is a rare cause of myocardial injury, has heterogeneous clinical presentations, and is likely underdiagnosed in critically ill patients with COVID-19. Because of the potential for rapid deterioration in COVID-19 patients with myocarditis, it is imperative to be aware of myocarditis as a sequela of COVID-19 and a multidisciplinary team should be formed for all COVID-19 patients with clinically suspected myocarditis. Further studies are needed to better recognize and understand the association of myocarditis and COVID-19.

\section{Funding Sources}

The authors have no funding sources to declare.

\section{Disclosures}

The authors have no conflicts of interest to disclose.

\section{References}

1. World Health Organization. WHO Director-General's remarks at the media briefing on 2019-nCoV on 11 February 2020. Available at: https://www.who.int/dg/speeches/detail/who-director-general-s-remarksat-the-media-briefing-on-2019-ncov-on-11-february-2020. Accesssed May 20, 2020.

2. Wu Z, McGoogan JM. Characteristics of and important lessons from the coronavirus disease 2019 (COVID-19) outbreak in China: summary of a report of 72314 cases from the Chinese Center for Disease Control and Prevention. JAMA 2020;2019:2-5.

3. Shi S, Qin M, Shen B, et al. Association of cardiac injury with mortality in hospitalized patients with COVID-19 in Wuhan, China [e-pub ahead of print]. JAMA Cardiol, https://doi.org/10.1001/jamacardio.2020.0950, accessed May 20, 2020.

4. Xu Z, Shi L, Wang Y, et al. Pathological findings of COVID-19 associated with acute respiratory distress syndrome. Lancet Respir Med 2020;8:420-2.

5. Zeng JH, Liu YX, Yuan J, et al. First case of COVID-19 complicated with fulminant myocarditis: a case report and insights. Infection 2020: $1-5$. 
6. Alhogbani T. Acute myocarditis associated with novel Middle east respiratory syndrome coronavirus. Ann Saudi Med 2016;36:78-80.

7. Inciardi RM, Lupi L, Zaccone G, et al. Cardiac involvement in a patient with coronavirus disease 2019 (COVID-19) [e-pub ahead of print]. JAMA Cardiol https://doi.org/10.1001/jamacardio.2020.1096, accessed May 20, 2020.

8. Hu H, Ma F, Wei X, Fang Y. Coronavirus fulminant myocarditis saved with glucocorticoid and human immunoglobulin [e-pub ahead of print]. Eur Heart J https://doi.org/10.1093/eurheartj/ehaa190, accessed May 20, 2020.

9. Huang C, Wang Y, Li X, et al. Clinical features of patients infected with 2019 novel coronavirus in Wuhan, China. Lancet 2020;395:497-506.

10. Mehta P, Mcauley DF, Brown M, Sanchez E, Tattersall RS, Manson JJ, et al. Correspondence COVID-19 : consider cytokine storm syndromes and immunosuppression. Lancet 2020;395:1033-4.

11. Chen G, Wu D, Guo W, et al. Clinical and immunologic features in severe and moderate forms of coronavirus disease 2019. J Clin Invest 2020;130:2620-9.

12. Ukimura A, Izumi T, Matsumori A. A national survey on myocarditis associated with the 2009 influenza A (H1N1) pandemic in Japan. Circ J 2010;74:2193-9.

13. Tisoncik JR, Korth MJ, Simmons CP, et al. Into the eye of the cytokine storm. Microbiol Mol Biol Rev 2012;76:16-32.

14. Mahallawi WH, Khabour OF, Zhang Q, Makhdoum HM, Suliman BA. MERS-CoV infection in humans is associated with a pro-inflammatory Th1 and Th17 cytokine profile. Cytokine 2018;104:8-13.

15. Reddy J, Massilamany C, Buskiewicz I, Huber SA. Autoimmunity in viral myocarditis. Curr Opin Rheumatol 2013;25:502-8.

16. Turner AJ, Hiscox JA, Hooper NM. ACE2: from vasopeptidase to SARS virus receptor. Trends Pharmacol Sci 2004;25:291-4.

17. Keidar S, Kaplan M, Gamliel-Lazarovich A. ACE2 of the heart: from angiotensin I to angiotensin (1-7). Cardiovasc Res 2007;73:463-9.

18. Tavazzi G, Pellegrini C, Maurelli M, et al. Myocardial localization of coronavirus in COVID-19 cardiogenic shock. Eur J Heart Fail 2020;22: 911-5.

19. Guo T, Fan Y, Chen M, et al. Cardiovascular implications of fatal outcomes of patients with coronavirus disease 2019 (COVID-19) [e-pub ahead of print]. JAMA Cardiol https://doi.org/10.1001/jamacardio. 2020.1017, accessed May 20, 2020.

20. Ruan Q, Yang K, Wang W, Jiang L, Song J. Clinical predictors of mortality due to COVID-19 based on an analysis of data of 150 patients from Wuhan, China. Intensive Care Med 2020;46:846-8.

21. Caforio ALP, Pankuweit S, Arbustini E, et al. Current state of knowledge on aetiology, diagnosis, management, and therapy of myocarditis: a position statement of the European Society of Cardiology Working Group on Myocardial and Pericardial Diseases. Eur Heart J 2013;34: 2636-2648, 2648a-d.

22. Baboonian C, Treasure T. Meta-analysis of the association of enteroviruses with human heart disease. Heart 1997;78:539-43.

23. Li L, Huang T, Wang Y, et al. COVID-19 patients' clinical characteristics, discharge rate, and fatality rate of meta-analysis. J Med Virol 2020;92:577-83.

24. Fairweather D, Cooper LTJ, Blauwet LA. Sex and gender differences in myocarditis and dilated cardiomyopathy. Curr Probl Cardiol 2013;38: 7-46.
25. Akhmerov A, Marban E. COVID-19 and the Heart. Circ Res 2020;126: 1443-55.

26. Zhou F, Yu T, Du R, et al. Clinical course and risk factors for mortality of adult inpatients with COVID-19 in Wuhan, China: a retrospective cohort study. Lancet 2020;395:1054-62.

27. Rivara MB, Bajwa EK, Januzzi JL, et al. Prognostic significance of elevated cardiac troponin-T levels in acute respiratory distress syndrome patients. PLoS One 2012;7:e40515.

28. Ukena C, Mahfoud F, Kindermann I, et al. Prognostic electrocardiographic parameters in patients with suspected myocarditis. Eur J Heart Fail 2011;13:398-405.

29. He J, Wu B, Chen Y, et al. Characteristic electrocardiographic manifestations in patients With COVID-19. Can J Cardiol 2020;36:966.e1-4.

30. Bière L, Piriou N, Ernande L, Rouzet F, Lairez O. Imaging of myocarditis and inflammatory cardiomyopathies. Arch Cardiovasc Dis 2019;112:630-41.

31. Felker GM, Lee KL, Bull DA, et al. Diuretic strategies in patients with acute decompensated heart failure. N Engl J Med 2011;364:797-805.

32. Covid- T, Society C. Practice of echocardiography during the COVID19 pandemic: guidance from the Canadian Society of Echocardiography. 2020;1-4. Available at: http://csecho.ca/wp-content/uploads/2020/ 03/CSE-COVID-19-Guidance_English-1.pdf. Accessed March 30, 2020.

33. Ezekowitz JA, O’Meara E, McDonald MA, et al. 2017 Comprehensive update of the Canadian Cardiovascular Society guidelines for the management of heart failure. Can J Cardiol 2017;33:1342-433.

34. Friedrich MG, Sechtem U, Schulz-Menger J, et al. Cardiovascular magnetic resonance in myocarditis: a JACC white paper. J Am Coll Cardiol 2009;53:1475-87.

35. Han Y, Chen T, Bryant J, et al. Society for Cardiovascular Magnetic Resonance (SCMR) guidance for the practice of cardiovascular magnetic resonance during the COVID-19 pandemic. J Cardiovasc Magn Reson $2020 ; 22: 26$

36. Sala S, Peretto G, Gramegna M, et al. Acute myocarditis presenting as a reverse Tako-Tsubo syndrome in a patient with SARS-CoV-2 respiratory infection. Eur Heart J 2020;41:1861-2.

37. Doyen D, Moceri P, Ducreux D, Dellamonica J. Myocarditis in a patient with COVID-19: a cause of raised troponin and ECG changes. Lancet 2020;395:1516.

38. Coyle J, Igbinomwanhia E, Sanchez-Nadales A, et al. A recovered case of COVID-19 myocarditis and ARDS treated with corticosteroids, tocilizumab, and experimental AT-001 [e-pub ahead of print]. JACC Case Rep, https://doi.org/10.1016/j.jaccas.2020.04.025, accessed May 19, 2020.

39. Luetkens JA, Isaak A, Zimmer S, et al. Diffuse myocardial inflammation in COVID-19 associated myocarditis detected by multiparametric cardiac magnetic resonance imaging. Circ Cardiovasc Imaging 2020;13: $\mathrm{e} 010897$.

40. Kim IC, Kim JY, Kim HA, Han S. COVID-19-related myocarditis in a 21-year-old female patient. Eur Heart J 2020;41:1859.

41. Yao XH, Li TY, He ZC, et al. A pathological report of three COVID-19 cases by minimally invasive autopsies [in Chinese]. Zhonghua Bing Li Xue Za Zhi 2020;49:411-7.

42. Frustaci A, Russo MA, Chimenti C. Randomized study on the efficacy of immunosuppressive therapy in patients with virus-negative inflammatory cardiomyopathy: the TIMIC study. Eur Heart J 2009;30:1995-2002. 
43. Mason JW, O'Connell JB, Herskowitz A, et al. A clinical trial of immunosuppressive therapy for myocarditis. The Myocarditis Treatment Trial Investigators. N Engl J Med 1995;333:269-75.

44. Russell CD, Millar JE, Baillie JK. Clinical evidence does not support corticosteroid treatment for 2019-nCoV lung injury. Lancet 2020;395: 473-5.

45. Zhang Q, Wang Y, Qi C, Shen L, Li J. Clinical trial analysis of 2019nCoV therapy registered in China. J Med Virol 2020;92:540-5.

46. Tschöpe C, Cooper LT, Torre-Amione G, Van Linthout S. Management of myocarditis-related cardiomyopathy in adults. Circ Res 2019;124: 1568-83.

47. Cao B, Wang Y, Wen D, et al. A trial of lopinavir-ritonavir in adults hospitalized with severe Covid-19. N Engl J Med 2020;382:1787-99.
48. Acker MA. Mechanical circulatory support for patients with acutefulminant myocarditis. Ann Thorac Surg 2001;71(3 suppl):S73-6 [discussion: S82-5].

49. Yang $X, Y u Y, X u$ J, et al. Clinical course and outcomes of critically ill patients with SARS-CoV-2 pneumonia in Wuhan, China: a singlecentered, retrospective, observational study. Lancet Respir Med 2020;8: 475-81.

50. Wang D, Hu B, Hu C, et al. Clinical characteristics of 138 hospitalized patients with 2019 novel coronavirus-infected pneumonia in Wuhan, China. JAMA 2020;323:1061-9.

51. Siripanthong B, Nazarian S, Muser D, et al. Recognizing COVID-19related myocarditis: the possible pathophysiology and proposed guideline for diagnosis and management [e-pub ahead of print]. Heart Rhythm https://doi.org/10.1016/j.hrthm.2020.05.001. Accessed May 19, 2020 